\title{
REPRODUCTIVE BEHAVIOUR AND BIOLOGY OF OXYOPES CHITTRAE TIKADER (ARANEAE: OXYOPIDAE) OCCURRING ON COTTON
}

\author{
P.A. Sebastian, A.V. Sudhikumar and Samson Davis
}

Division of Arachnology, Department of Zoology, Sacred Heart College, Thevara, Kochi, Kerala 682013, India

\begin{abstract}
The paper presents the results of laboratory studies on the reproductive behaviour and biology of the Lynx Spider, Oxyopes chittrae Tikader found in cotton agroecosystems. The spider made a circular sperm web for sperm induction. A peculiar type of courtship behavior was exhibited. Mating lasted for 20-30 minutes. The female prepared 2-5 cocoons with an average of 3.5 cocoons in one season. The cocoon was lenticular in shape and attached to a twig or a leaf in a safe place. The female was found to take care of the eggs by sitting over them. Higher numbers of eggs were found in the first cocoon and the number decreased in the successive cocoons. Each cocoon contained an average of 25 eggs. The male took nine moults and the female 10 moults to mature. Male and female take an average of $194.28 \pm 5.51$ and $269.63 \pm 7.68$ days respectively for complete development. The total life span of the male was $287.18 \pm$ 3.46 days and the female was $396.03 \pm 2.87$ days. The total length attained by male and female was $7.54 \pm 1.94 \mathrm{~mm}$ and $7.84 \pm 2.37 \mathrm{~mm}$, respectively.
\end{abstract}

\section{Keywords}

Biology, Oxyopes chittrae, sperm induction

Spiders are amongst the most omnipresent and numerous predators in both agricultural and natural ecosystems. The importance of spiders in regulating insect pest population has been tacitly assumed by many arachnologists despite a dearth of supporting quantitative evidences. Spiders are highly abundant in agricultural fields and if they can be conserved or augmented can regulate many insect pests (Andow \& Rosset, 1990). As a group, they are highly resilient in agroecosystems, long-lived and readily seek out new fields after harvest. They feed almost exclusively on insects, but little attention has been paid to their possible use in insect pest suppression (Riechert $\&$ Bishop, 1990). The high rate of reproduction and adaptability to the conditions of a particular habitat have taken them into the front line of the natural enemy complex of insect pests. The potential of spiders as natural control agents of arthropod pests has aroused interest in learning more about them, viz., biology, behaviour and abundance in different ecosystems (Riechert \& Lockley, 1984). Nyffeler et al. (1987) evaluated the importance of Striped Lynx Spider Oxyopes salticus in Texas cotton fields. In 1975, Gavarra and Raros studied the life cycle, courtship behaviour and cocoon spinning of Lycosa pseudoannulata. Sadana (1972) studied the mechanism of copulation in Lycosa chaperi. Eason and Whitcomb (1967) studied the life history and predatory importance of Striped Lynx Spider including its biology and ecology. Dhulia and Yadav (1994) studied the biology of Indian Lynx Spider Oxyopes ratnae occurring on cotton. Oxyopidae is a large cosmopolitan family, which has traditionally been viewed as one of the major groups of nonvisual cursorial hunting spiders; little detailed information is available on the biology and reproductive behavior of these spiders (Barnes, 1980).

A study to understand the reproduction of Oxyopes chittrae Tikader was made to compare with the reproduction of hunting spiders that have already been extensively studied (Enders, 1976). The aim of our study was to ascertain the behaviours associated with sperm induction, courtship and cocoon spinning and life history of this spider.

\section{Materials And Methods}

The females of Oxyopes chittrae Tikader were collected from the cotton fields of northern Gujarat region $\left(21^{\circ} 58^{\prime}-24^{\circ} 30^{\prime} \mathrm{N} \&\right.$ $\left.71^{\circ} 16^{\prime}-73^{\circ} 25^{\prime} \mathrm{E}\right)$ of western India and kept in $1 \mathrm{~L}$ glass jars. The mouth of the glass jar was covered with a fine nylon cloth. Females were fed with laboratory-reared larvae of Corcyra cephalonica Staint and Spodoptera littura Fab. The eggs laid by such females were used to study the incubation period and other biological characters. The studies were carried out at 25$30^{\circ} \mathrm{C}$. The relative humidity was maintained between 60 and $80 \%$ throughout rearing, by inserting moistened wad of cotton. The incubation period of the eggs were studied in the same jar. The egg masses were examined daily and the duration of hatching as well as number of spiderlings were recorded.

The newly hatched spiderlings were transferred to a clean glass vial $(10 \times 2.5 \mathrm{~cm})$ using a fine camel hairbrush and the mouth of the glass vial was plugged with a cotton plug. A cotton swab soaked in water was placed inside the glass vial to maintain humidity. The spiderlings were fed with nymphs of aphids (Aphis craccivora) collected from field for the first few days. They were given 3-7 newly hatched larvae of $C$. cephalonica regularly until they reached the second instar followed by $4-5$ days old larvae of $C$. cephalonica (5-6 individuals). Slightly grown larvae were given as the development of spiderlings advanced. The food remains and excreta were removed every day and the cotton swab was replaced every alternate day. The glass vials were also cleaned periodically. The development of spiderlings was closely observed under a stereo-zoom microscope (Leica MS-5).

To study mating behavior, a pair of male and female was retained in $1 \mathrm{~L}$ glass jar. A small twig of cotton plant was placed in the jar to provide natural substrate. Temperature and humidity were maintained properly. Mating behavior and cocoon spinning were closely observed. Since parental care is often seen in spiders, close observations were made to study this behaviour in the laboratory. 


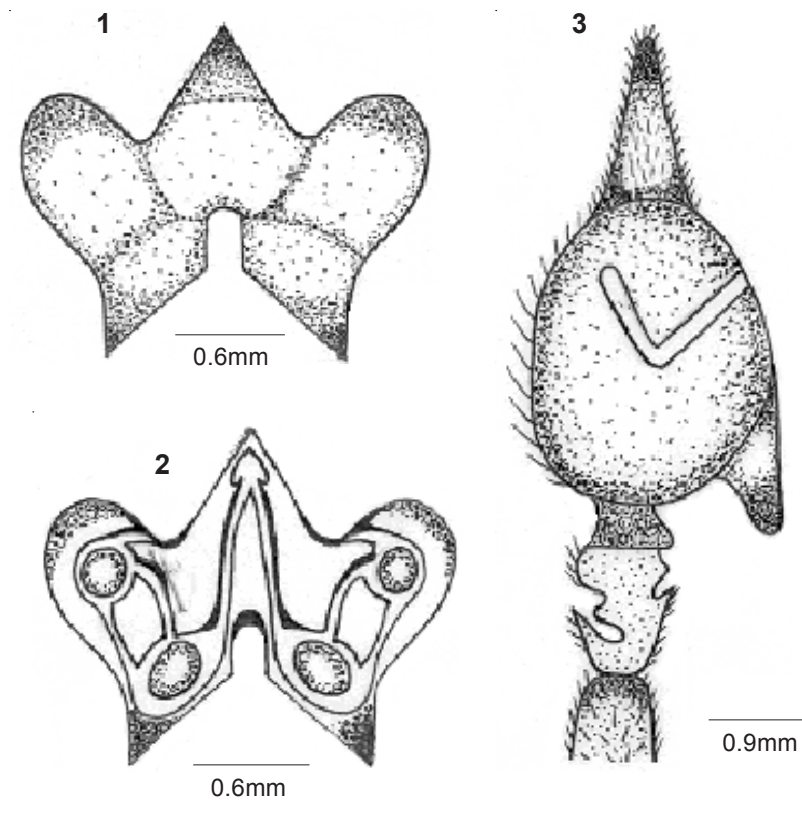

Figures 1-3. Oxyopes chittrae Tikader 1 - Epigyne; 2 - Internal genitalia; 3 - Pedipalp

\section{Results \\ Sperm induction}

Following the final moult, the male charged his palps with semen. The male prepared a circular sperm web that was often attached to the substratum. After the completion of the sperm web, the male deposited a tiny drop of semen in the center of the web on the dorsal side after the speedy up and down movements of the abdomen. Then the palps were brought to the sperm drop and charged alternately. It took 7-19 minutes to charge the palps.

\section{Courtship and mating}

The male recognized the presence of the female by turning towards her, raising his cephalothorax and drumming his palps. If she was acceptive, she moved her palps up and down alternately once or twice. The courtship lasted for 15-30 minutes. Then both male and female came very close, facing each other and the male came in contact with the female by his anterior legs. Then the male approached the side of the female and mounted her from the front, or directly from behind. The male then moved over the abdomen of the female, stretched the palps laterally downwards to reach the epigynal orifice. He leaned towards the direction while inserting the left and the right palps. The left palp was inserted into the left genital orifice and right palp into the right genital orifice. Mating lasted for 20-30 minutes.

\section{Cocoon spinning}

The female began to prepare her first cocoon after 5-15 days of mating. The female located a safer place, below the leaves, on twigs or on the ground where she started preparing a disk consisting of soft silk. She hung from the leaves or twigs up side down with her body parallel to the ground. All spinning was done at night by movements of the abdomen. When the disk was completed, the female paused for some time, and forced her eggs upward against the disc. She then spun across the eggs and rapidly covered them. Finally, the cocoon acquired a lenticular shape and was attached to twigs or leaves. The entire process took 60-105 minutes. The mother guarded the cocoon by clinging to the side till the spiderlings emerged out. The female prepared 2-5 cocoons (the average being 3.5 cocoons) in one season. Successive cocoons were prepared with an interval of 20-48 days. Higher numbers of eggs were found in the first cocoon and the number decreased in the successive cocoons. Each cocoon contained an average of 25 eggs with a minimum of 11 to a maximum of 49 eggs. One female laid an average of 97 eggs in one season.

\section{Life history}

Eclosion occured about 10-15 days after cocoon formation. The first moult occured inside the cocoon itself. The transparent first instar spiderlings emerged out from the cocoon through a small hole at the side of the cocoon and then dispersed by ballooning. The male attained maturity after nine moults and the female after 10 moults. From the time of emergence, to attain maturity, the male took 179-221 days with an average of $194.28 \pm 5.51$ days, while in the case of females it was 249-293 days with an average of $269.63 \pm 7.68$ days. Instar duration and variation in different body parameters at different stadia is given in Table 1 while changes in leg length in different instars is given in Table 2. The life span extended from 254 to 311 days (average being 287.18 \pm 3.46 days) in males and 327 to 405 days (average being 396.03 \pm 2.87 days) in females. The average length of adult male was $7.54 \pm 1.94 \mathrm{~mm}$ and $7.84 \pm 2.37 \mathrm{~mm}$ in the case of females. Instar-wise growth rate changes of different body parameters in male and female $O$. chittrae is given in Figures 1-6. In the case of carapace growth rate, maximum growth rate was observed in $\mathrm{V}$ instar stage of male and VIII instar stage of female. Growth rate of abdomen decreased gradually and then increased. Both male and female showed similar pattern of growth rate tendency. First leg was the longest. The leg formula was $1>2>4>3$. All legs showed similar growth rate patterns.

\section{Discussion}

Oxyopes chittrae is an active hunting spider found on the foliage and on the ground in the fields. It hunts actively during day and builds no snares or retreats. One important feature in its development is that it moults only once inside the egg sac before emergence. This feature is true of Cheiracanthium

Table 1. Changes in leg length (in $\mathrm{mm}$ ) in different instars of spider Oxyopes chittrae reared in laboratory (average of 25 male and 25 female individuals).

\begin{tabular}{lllll}
\hline \multicolumn{2}{l}{ Instars*Leg-I } & Leg-II & Leg-III & Leg-IV \\
\hline II & $02.19(02.83)$ & $02.01(02.76)$ & $01.86(02.33)$ & $01.88(02.57)$ \\
III & $03.94(05.67)$ & $02.48(04.22)$ & $01.87(03.26)$ & $02.16(04.11)$ \\
IV & $05.87(06.79)$ & $04.49(06.05)$ & $02.11(04.82)$ & $03.44(05.66)$ \\
V & $06.36(07.87)$ & $05.47(07.43)$ & $02.94(05.63)$ & $04.48(06.67)$ \\
VI & $07.78(08.42)$ & $06.58(08.32)$ & $03.76(06.48)$ & $05.68(07.64)$ \\
VII & $08.65(09.83)$ & $07.88(09.39)$ & $04.34(07.88)$ & $06.73(08.76)$ \\
VIII & $09.34(10.54)$ & $08.56(10.48)$ & $05.36(08.44)$ & $07.82(09.35)$ \\
IX & $10.14(11.66)$ & $09.12(11.34)$ & $07.47(09.32)$ & $08.32(10.39)$ \\
X & $00.00(14.30)$ & $00.00(13.70)$ & $00.00(11.90)$ & $00.00(13.42)$ \\
\hline
\end{tabular}


Table 2. Duration (in days) of instars and changes in carapace length, width and total length (in mm) of spider Oxyopes chittrae reared in laboratory (average of 25 male and 25 female individuals)

\begin{tabular}{|c|c|c|c|c|c|c|c|c|}
\hline \multirow[t]{2}{*}{ Instars } & \multicolumn{2}{|c|}{ Number of days } & \multicolumn{2}{|c|}{ Length of carapace } & \multicolumn{2}{|l|}{ Width of carapace } & \multicolumn{2}{|l|}{ Total length } \\
\hline & Range & Average & Range & Average & Range & Average & Range & Average \\
\hline II & $17-28(16-22)$ & $19.24(18.46)$ & $0.39-0.70(0.37-0.68)$ & $0.51(0.46)$ & $0.31-0.45(0.36-0.46)$ & $0.40(0.40)$ & $1.63-2.15(1.85-2.25)$ & $1.92(2.25)$ \\
\hline III & $19-50(24-43)$ & $24.65(29.67)$ & $0.53-0.82(0.64-0.85)$ & $0.65(0.79)$ & $0.43-0.71(0.55-0.75)$ & $0.61(0.69)$ & $2.01-2.58(2.74-3.21)$ & $2.46(3.21)$ \\
\hline IV & $11-21(22-35)$ & $18.25(24.75)$ & $0.81-1.21(0.95-1.25)$ & $1.15(1.20)$ & $0.69-0.95(0.76-1.01)$ & $0.89(0.99)$ & $2.38-3.56(3.81-4.25)$ & $3.35(3.81)$ \\
\hline V & $23-37(23-56)$ & $28.73(36.83)$ & $1.11-1.82(1.15-1.71)$ & $1.70(1.55)$ & $0.87-1.25(1.15-1.40)$ & $1.21(1.25)$ & $3.41-4.20(4.11-4.91)$ & $4.15(4.45)$ \\
\hline VI & $25-39(29-66)$ & $29.90(42.67)$ & $1.69-2.21(1.69-2.11)$ & $1.86(1.99)$ & $1.15-1.71(1.43-1.76)$ & $1.63(1.56)$ & $4.11-4.99(4.62-4.99)$ & $4.61(4.92)$ \\
\hline VII & $20-41(23-45)$ & $32.34(34.89)$ & $2.08-2.55(2.14-2.53)$ & $2.33(2.26)$ & $1.51-1.95(1.70-2.05)$ & $1.92(2.00)$ & $4.81-5.62(5.31-5.95)$ & $5.56(5.81)$ \\
\hline VIII & $15-30(25-46)$ & $22.52(33.34)$ & $2.42-2.95(2.43-2.85)$ & $2.71(2.75)$ & $1.89-2.25(2.15-2.43)$ & $2.21(2.31)$ & $5.46-6.89(6.45-6.89)$ & $6.43(6.83)$ \\
\hline IX & $11-24(19-460$ & $18.65(26.66)$ & $2.89-3.36(2.71-3.15)$ & $3.10(2.95)$ & $2.15-2.71(2.45-2.81)$ & $2.52(2.70)$ & $6.51-7.82(7.21-8.26)$ & $7.54(7.84)$ \\
\hline$X$ & $00-00(12-30)$ & $00.00(22.36)$ & $0.00-0.00(2.96-3.49)$ & $0.00(3.26)$ & $0.00-0.00(2.65-3.11)$ & $0.00(2.95)$ & $0.00-0.00(8.99-9.99)$ & $0.00(9.71)$ \\
\hline
\end{tabular}

S.D.: 5.51; S.D.: 7.68; Total developmental period of male: 179-221 194.28; Total developmental period of female: $249-293$ (269.63); Total life span of male: 254-311 days; Total life span of female: 327-405 days

inclusum (Clubionidae) (Peck \& Whitcomb, 1970) and Tetragnatha laboriosa (Teragnathidae) (Le Sar \& Unzicker, 1978). Spider life cycle ranges from rapidly maturing species, which can produce two generations per year up to long-lived species, which requires ten years to reach maturity. However, most spiders maintain a more or less annual cycle (Levy, 1970). Males and females usually take a similar length of time to reach maturity, but life span of female is often somewhat longer than males (Levy, 1970). Levy has classified the life cycle of spiders into two life cycle groups and $O$. chittrae seems to fit the first group, which includes spiders in which mates are derived from cocoons laid about the same time. Within this group, O. chittrae would belong to the second group of Bonnet (1935) where eggs are laid in spring or summer; spiderlings attain an immature stage, over winter and reach maturity in the next spring or summer. But if females of $O$. chittrae survive to lay eggs in the following summer, then it is possible that they will mate with the males that developed from eggs laid in the preceding season. Indeed, it is possible (although very unlikely given wide dispersal) that they could mate with their own sons.

Copulation sometimes follows contact behaviour or noncontact behaviour. The contact behaviour includes the stroking with palps and legs of sexual partners, thus making a physical contact with each other. Interactions normally begin with noncontact behaviour, such as plucking of the web and female charging or lurking towards the male. In most of the spiders vision seems to be of little or no significance except in salticids (Jackson, 1978). It can be presumed that the communication is primarily by means of vibratory signals transmitted through the silk threads during the non-contact behaviour and the tactile and chemotactic signals during the contact behaviour. The cocoon-spinning behaviour is a good example of succession of instinctive responses controlled by both external and internal stimuli. The sequences of different behavioural stages such as platform preparation, oviposition and concealment of eggs follow one after the other as organized that none of the stage is omitted or no stage is separated again in normal course (Bradoo, 1975; Opell, 1979; Patel \& Bradoo, 1980).

It was observed that the abundance of food increases the production of greater number of cocoons and as such the number of eggs (Hagstrum, 1970). Scarcity of food was found to prolong the time interval of successive cocoon formations and resulted in the reduction of silk production, which in turn influenced the complete concealing of the egg mass and the production of the number of eggs. The placing of cocoons near or in the vicinity of the mother's resting place, when not carried by the mother reduced the chances of predation of eggs.

\section{REFERENCES}

Andow, D.A. and P.M. Rosset (1990). Integrated pest management. Mc Graw Hill Publishers, New York, 1016pp.

Barnes, R.D. (1980). Invertebrate Zoology. Saunders Publishers, Philadelphia, 883pp.

Bonnet, P. (1935). La longevite chez les Araginees. Bulletin of Entomological Society of France 40(2): 272-277.

Bradoo, B.L. (1975). The cocoon spinning behavior and fecundity of Stegodyphus sarsinorum Karsch (Araneae: Eresidae) from India. Journal of Bombay Natural History Society 72(2): 392-400.

Dhulia, F.K. and D.N. Yadav (1994). Observation on the biology of Oxyopes ratnae Tikader (Arachnida: Oxyopidae) occurring on cotton. Journal of Biological Control 8(2): 94-97.

Enders, F. (1976). Clutch size related to hunting manner of spider species. Annals of Entomological Society of America 69(6): 991-998. Gavarra, M.R. and R.S. Raros (1975). Studies on the biology of the predatory Wolf Spider, Lycosa pseudoannulata (Araneae: Lycosidae). Phillippine Entomologist 2(6): 427-444.

Hagstrum, D. (1970). Ecological energetics of the spider Tarentula kochi (Araneae: Lycosidae). Annals of Entomological Society of America 63(4): 1297-1304.

Jackson, R.R. (1978). Life history of Phidippus johnsoni (Araneae: Salticidae). Journal of Arachnology 6(1): 1-29.

Le Sar, C.D. and J.D. Unzicker (1978). Life history, habits and prey preference of Tetragnatha laboriosa (Araneae: Tetragnathidae). Environmental Entomology 7(6): 879-884.

Levy, G. (1970). The life cycle of Thomisus onustus (Araneae: Thomisidae) and outlines for the classification of the life histories of spiders. Journal of Zoology 160(2): 523-536.

Nyffeler, M, D.A. Dean and W.L. Sterling (1987). Evaluation of importance of the Striped Lynx Spider Oxyopes salticus (Araneae: Oxyopidae) as a predator in Texas Cotton. Environmental Entomology 16(1): 1114-1123.

Opell, B.D. (1979). Book review "Biology of Spiders" by R.F. Foelix. Science 218 (46).

Patel, B.H. and B.L. Bradoo (1980). The cocoon spinning behavior and maternal care in Uloborus ferokus (Araneae: Uloboridae). Annals of Zoology 207(1): 78-87.

Peck, W.B. and W.H.Whitcomb (1970). Studies on the biology of a spider, Clubiona inclusum (Hentz.). Bulletin of Arkansas Agriculture 

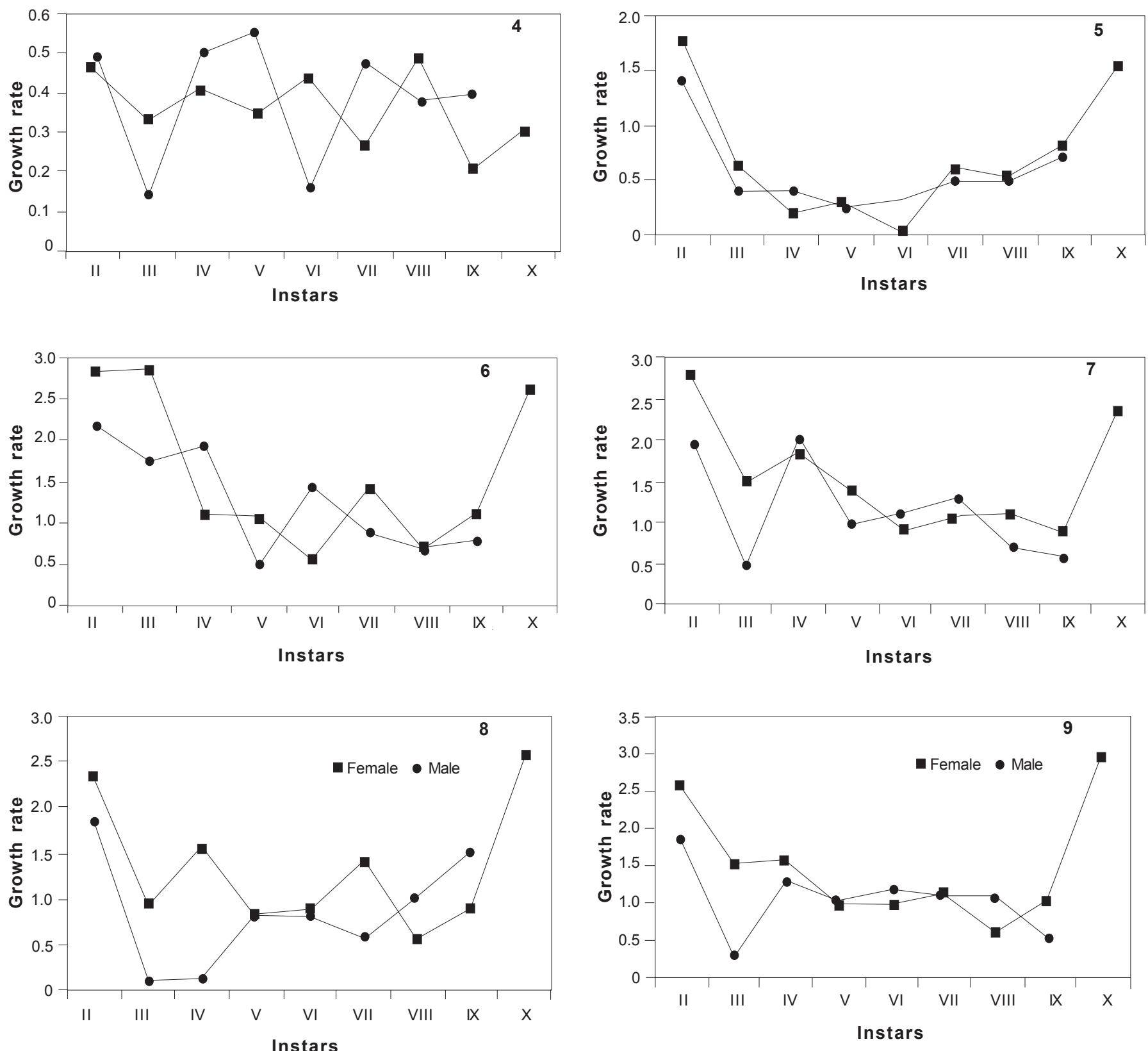

Figures 4-9. Instar-wise growth rate changes of different body parameters in male and female Oxyopes chittrae 4 - Carapace; 5 - Abdomen; 6 - I Leg; 7 - II Leg; 8 - III Leg ; 9 - IV Leg

Experimental Station No. 753: 1-76.

Riechert, S.E. and L. Bishop (1990). Prey control by an assemblage of generalist predators: Spiders in a garden test system. Ecology 71(2): 1441-1450. Riechert, S.E. and T. Lockley (1984). Spiders as biological control agents. Annual Review of Entomology 29(3): 299-320.

Sadana, G.L. (1972). Mechanism of copulation in Lycosa chaperi (Araneae: Lycosidae). Bulletin of British Arachnological Society 2(5): 87-89.

Tikader, B.K. (1965). On some new species of spiders of the family Oxyopidae from India. Proceedings of the Indian Academy of Science 62: 140-144.

Whitcomb, W.H. and R. Eason (1967). Life history and predatory importance of the Striped Lynx Spider. Proceedings of the Arkansas Academy of Science 21(1): 54-58.

\section{ACKnowledgements}

First author is grateful to ICAR for financial assistance towards the study. 